\title{
Salammbô dans les arts, G. Séginger (dir.)
}

\section{Ida Merello}

\section{(2) OpenEdition}

\section{Journals}

\section{Edizione digitale}

URL: http://journals.openedition.org/studifrancesi/10023

DOI: 10.4000/studifrancesi. 10023

ISSN: 2427-5856

\section{Editore}

Rosenberg \& Sellier

\section{Edizione cartacea}

Data di pubblicazione: 1 août 2017

Paginazione: 387-388

ISSN: 0039-2944

\section{Notizia bibliografica digitale}

Ida Merello, «Salammbô dans les arts, G. Séginger (dir.)», Studi Francesi [Online], 182 (LXI | II) | 2017,

online dal 01 août 2017, consultato il 05 janvier 2021. URL: http://journals.openedition.org/ studifrancesi/10023 ; DOI: https://doi.org/10.4000/studifrancesi.10023

\section{Questo documento è stato generato automaticamente il 5 janvier 2021}

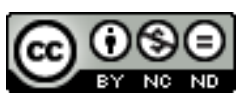

Studi Francesi è distribuita con Licenza Creative Commons Attribuzione - Non commerciale - Non opere derivate 4.0 Internazionale. 


\title{
Salammbô dans les arts, G. Séginger (dir.)
}

\author{
Ida Merello
}

\section{NOTIZIA}

Salammbô dans les arts, sous la direction de Gisèle SÉGINGER, Paris, Classiques Garnier, 2016, «La Revue des Lettres modernes» 8, 383 pp.

1 Nell'introduzione Gisèle SÉGINGER ricorda la mole di studi compiuti per la Salammbô da Flaubert, che riteneva altrettanto indispensabile dopo tanto lavoro «une belle semaine de forte rêverie» e come il suo romanzo sia entrato capillarmente nella memoria collettiva, attraverso rappresentazioni artistiche e teatrali, incoraggiate dall'autore che però rifiutava un'edizione illustrata.

2 Gilles Soubigou, Multiples Salammbô. Réception et interprétation du roman de Flaubert dans les arts visuels, pp. 21-49, presenta i diversi approcci figurativi a Salammbô dopo la morte di Flaubert, con un importante annesso dell'elenco delle opere artistiche ispirate al romanzo e attenzione ai rapporti che si vengono a stringere con l'ornamentazione e il gusto della linea flessuosa Art Nouveau.

3 Véronique DUMAS, Flaubert et Gustave Moreau: de Salammbô à Salomé, pp. 51-72, mette in evidenza i rapporti di reciproca stima tra i due autori - anche se Moreau non voleva farsi illustratore di Flaubert - uniti dal medesimo bisogno di vivere isolati, per quanto Moreau abitasse in piena Parigi. Flaubert non aveva forse ancora conosciuto le opere di Moreau al momento della stesura del romanzo, ma le similitudini tra Salammbô e Salomé sono evidenti per gli autori dell'epoca: Des Esseintes le accomuna nel medesimo immaginario e Jean Lorrain vi vede l'espressione della femme fatale. L'A. conclude con un'indagine sulle diverse componenti mitiche in essa presenti.

4 Pierre sÉRIÉ, Du sang sur les marches: peindre l'histoire après Salammbô, pp. 91-106, compie uno studio sulle opere pittoriche ispirate al romanzo, che compaiono poco dopo la sua 
pubblicazione, mostrando l'evoluzione della pittura di storia: a differenza dall'ordinario intento morale, vi è una maggiore attenzione alla qualità artistica di per sé.

Bruna DONATELLI, La Salammbô de Philippe Druillet. Entre beauté spatiale et beauté ancestrale, pp. 123-134, presenta l'autore di bandes dessinés e quadri ispirati a Salammbô, incentrati sulla ripetizione del nudo.

6 Nigel HARKNESS, Sculpter Salammbô, pp. 135-168, mostra come l'attenzione scultorea di Flaubert abbia sollecitato tra il 1869 e il 1900 la produzione di numerosi gruppi sculturali, in bassorilievi, statue, busti e medaglie, aventi per oggetto la coppia di protagonisti o Salammbô col pitone, ma anche scene di guerra. L'A. offre un repertorio analitico importante per comprendere la portata dell'influenza del romanzo.

7 Nathalie PEtitbon, L'acoustique de Carthage, Salammbô à l'opéra, pp. 169-192, sottolinea l'attenzione ai diversi suoni nel romanzo di Flaubert, che compongono di per sé una sorta di sinfonia atonale, ma stimolano anche la resa musicale del testo. L'A. compie una capillare ricognizione dei diversi progetti di opera lirica, da Giuseppe Verdi a Mussorgsky, e delle realizzazioni, da Reyer (1890) a Philippe Fénelon e Jean-Yves Masson (1890).

8 Cécile REYNAUD, Salammbô de Reyer, pp. 193-220, concentra la sua attenzione sull'opera di Reyer, ricordando i diversi passaggi che hanno portato alla scelta di Du Locle come librettista, dopo il mancato esito della collaborazione con Gautier e la lite con Mendès. La corrispondenza tra Du Locle e Reyer rivela come il primo non avesse lo spirito devozionale di Gautier e Mendès nei confronti di Flaubert, e un confronto tra gli scénario di Flaubert e Du Locle, fino a quello definitivo, fa emergere tutte le libertà che Du Locle si permette.

9 Loïc CHEVALIER, Salammbô à L'Ecran. La poétique générique a eu raison de Flaubert, pp. 221-236, presenta due adattamenti cinematografici: di Pierre Marodon, per il film muto, nel 1925, e di Sergio Grieco nel 1960. Subito l'A. sottolinea la contraddizione fondamentale: Flaubert aveva scelto la storia cartaginese per la mancanza di documentazione al riguardo, che ne rendeva possibile una mitizzazione; mentre il cinema attualizza la storia. Scende quindi nell'analisi dei due lavori, inserendo quello di Marodon nella corrente europea che si voleva alternativa a Hollywood, e quello di Grieco nella dissoluzione del genere storico, per il prevalere dell'avventura in sé.

Jacques NEEFS, Echos de l'étrange: quelques curiosités en mémoire de Salammbô, pp. 237-246, offre una piacevole spigolatura tra giudizi su Salammbô (George Sand, Banville, Huysmans), la moda degli abiti alla cartaginese, il gusto suggerito dal romanzo dell'inserzione di pietre e metalli nelle sculture (a partire da Théodore Rivière), l'influenza che Satie dichiarava sulle sue Gymnopédies, e una manciata di allusioni, riprese, citazioni esplicite e implicite in altri testi (Laforgue, Montesquieu, Jules Renard, il Conrad di The Nigger of the Narcissus, Glissant).

11 Nella sezione «Varia»: Atsuko OGANE, La danse de Salomé. Mise en abyme et métamorphoses des figures mythiques, pp. 251-270, rende conto dei progetti di Flaubert per la danza in Hérodias, con particolare attenzione agli aspetti simbolici.

12 Didier PHILIPPoT, "Hérodias", ou le promontoire du songe. Flaubert et la «vision poétique», pp. 271-314, affronta il motivo della visione in Hérodias partendo da riflessioni sul rapporto tra mimesi e realtà. Se, da Kant in poi, la rappresentazione è percepita come opposizione, distacco, lontananza dalla realtà, al contrario, secondo l'A., la prosa di Flaubert, in cui Proust vede più la manifestazione dell'impressione che dell'azione, non 
rimanda a una referenza esterna, né a un libro sul nulla. È sullo stesso piano della natura, altrettanto reale e autonoma perché opera dell'immaginazione creatrice. La novella di Hérodias viene interpretata alla luce di queste convinzioni come una visione che si incarna nella parola, che fissa un miraggio attraverso i procedimenti delle tecniche narrative. 